\title{
Research on Market Competitiveness of Cultural Industry in China's Minority Regions
}

\author{
Hou Yu; Han Yu; Ning Yunxia; Li Hongyun \\ Shijiazhuang Information Engineering Vocational College, Shijiazhuang Hebei China 050035
}

\begin{abstract}
At present, the development of China's cultural industry in minority regions has the following characteristics: firstly, the gap between interregional zones and internal zones is larger, but the speed of overall development is faster; secondly, effectively promote the regional employment and economic development, but the industrial structure is unreasonable; thirdly, the cultural resources with characteristics is abundant, but the cultural infrastructure is backward. This paper aims at putting forward some salutary strategies to promote cultural industry's market competitiveness in minority regions.
\end{abstract}

Key words: cultural industry; market competitiveness; minority regions.

\section{Introduction}

With the development of scientific technology and the coming of knowledge-economic era, the world economic trend of "structure softening" emerges. Knowledge and technology intensive industries instead of labor and capital intensive industries day by day, and the development mode of depending on mental labor and knowledge consumption replace the development mode of manual labor and material resources consumption gradually. Cultural industry enjoys popularities of various countries by means of the characteristics such as advanced scientific technology, low consumption, low pollution, short life cycle, cost effectiveness and stronger adsorption employment ability, as well as the advantages of knock-on effect of radiation to other industries, and shows a great tension in the aspects of economic development, stimulating employment, social progress, and elevation of comprehensive competitiveness.

China's minority regions have extremely abundant cultural resources and possess better bases of cultural industry development, but at present, the added value of cultural industry as a share of GDP is less than 3\%, and it is far away from the object in the new period which is "promoting cultural industry and letting it become the pillar industry of national economy." Currently, the whole level of China's per capita GDP has already exceeded \$3000, and the per capita GDP of the western minority regions is in the transitional period of $\$ 2000$ to $\$ 3000$. According to the practical experience of developed countries, the economy in this period is in the rapid development of cultural industry, and this is one of internal motivations to develop cultural industry in western minority regions. Moreover, great cultural differences exist between minority regions and other areas. This "other culture" is another impetus of cultural industry in minority regions. Meanwhile, minority regions are still facing some constraints such as the lack of human resources, backward science and technology levels, inadequate infrastructures, etc. therefore, how to take full advantage of advantageous conditions of cultural industry development in minority regions during the new tactic period of west development and the period of post-financial crisis is the major subject of the minority region.

\section{The Development Characteristics of Cultural Industry in China's Minority Regions}

Minority regions indicate the areas where different minority nationalities live together. The territorial scopes mainly include five national autonomous regions, furthermore, the three non-autonomous regions including Guizhou Province, Yunnan Province and Qinghai Province enjoy equal ethnic policies with autonomous regions in the respect of economic social development, so, they are also on the list of minority regions. The following contents are the analyses of the development characteristics of cultural industry in China's minority regions.

\subsection{The Regional Disparity is still Obvious, but the Speed of Development is Faster.}

China's developments of cultural industry have much relevance to economic developments. According to the research on the cultural industry competitiveness in China's east-central-west regions did by the Justin O'connor Culture Media Originality Industry Research Center, the scores of the cultural industry competitiveness in China's eastern, central and western are 6.276 points, 0.233 point, and -2.477 points respectively, and the regional disparity is obvious. Moreover, the distributions of China's national cultural 
Table 1. The Added Values of Cultural Industry in China's Minority Regions from 2001 to 2009 Unit: 1000 yuan/\%

\begin{tabular}{|c|c|c|c|c|c|c|c|c|c|}
\hline Year & $\begin{array}{c}\text { Inner } \\
\text { Mongolia }\end{array}$ & Guangxi & Guizhou & Yunnan & Tibet & Qinghai & Ningxia & Xinjiang & $\begin{array}{c}\text { Minority } \\
\text { regions }\end{array}$ \\
\hline $\mathbf{2 0 0 1}$ & 420490 & 566122 & 746771 & 1243044 & 84317 & 124579 & 123276 & 502326 & 3810925 \\
\hline $\mathbf{2 2 0 2}$ & 623354 & 1839299 & 795460 & 1464912 & 410835 & 177437 & 188833 & 627741 & 6127871 \\
\hline $\mathbf{2 0 0 3}$ & 705487 & 1045461 & 497717 & 1804916 & 437261 & 147048 & 207221 & 729149 & 5574260 \\
\hline $\mathbf{2 0 0 4}$ & 770691 & 1831533 & 729030 & 1591931 & 145393 & 154915 & 794535 & 1365776 & 7383809 \\
\hline $\mathbf{2 0 0 5}$ & 1105618 & 1684034 & 906703 & 2007679 & 402055 & 199512 & 376191 & 1046133 & 7727925 \\
\hline $\mathbf{2 0 0 6}$ & 1331951 & 1921057 & 1035007 & 2757591 & 83960 & 214445 & 417226 & 1170232 & 8931169 \\
\hline $\mathbf{2 0 0 7}$ & 2022068 & 2838608 & 1650634 & 3272175 & 714325 & 302189 & 788528 & 1595877 & 13184404 \\
\hline $\mathbf{2 0 0 8}$ & 1793509 & 2772857 & 1734596 & 2755879 & 376531 & 349360 & 797001 & 1627538 & 12197271 \\
\hline $\mathbf{2 0 0 9}$ & 2261336 & 2731248 & 1481721 & 2320159 & 455835 & 502951 & 665289 & 1369423 & 11787962 \\
\hline $\begin{array}{c}\text { Annual } \\
\text { growth rate }\end{array}$ & $20.50 \%$ & $19.11 \%$ & $7.90 \%$ & $7.18 \%$ & $20.62 \%$ & $16.77 \%$ & $20.60 \%$ & $11.79 \%$ & $13.37 \% \%$ \\
\hline
\end{tabular}

industry parks have the similar characteristics. At present, China has established 1216 national cultural industry parks, among which the amounts in Guangdong, Shanghai, Jiangsu exceeded more than 100, and they belong to the first tier; the amounts in the provinces of Henan, Fujian, Sichuan, Hebei exceeded 50, and these provinces belong to the second tier; other provinces basically belong to the third tier. In the view of the proportion of the output value and the added value of cultural industry, the cultural industry in Beijing, Shanghai, Guangdong as a share of GDP basically exceeded $8 \%$, but the share of minority regions generally below 3\%. This shows China's cultural industries present the pattern of "higher in the east and lower in the west" on the whole.

Although the cultural industry developments in China's minority regions have great disparity compared with the eastern regions, the development of cultural industry in minority regions is speeding up in recent years, and the scale is enlarging continuously. According to the data from China's Cultural Relics Statistical Yearbook, the added value of cultural industry in minority regions in 2009 as a share of the total was about $16 \%$. The added values of cultural industries in China's eight minority regions were 3.810925 billion yuan, and increased to 11.787962 billion yuan in 2009 , the average annual growth rate is $13.37 \%$, above the national average level of $3 \%$ points. The average annual growth rate of cultural industries in the three autonomous regions including Ningxia, Tibet, Inner Mongolia in nearly 9 years is above $20 \%$, higher bout $7 \%$ points than the average growth rate of minority regions, in 2009, the added values are 665.289 million yuan, 4558.35million yuan, and 22613.36 yuan respectively. In the view of added values of cultural industries, the cultural industries in Yunnan and Guangxi have better developments. The added values of cultural industries are 1243.044 million yuan and 566.122 million yuan in 2001 respectively, 14.7 times and 6.7 times the Tibet's 84.317 million yuan respectively. In 2009, the added values of cultural industries in Guangxi and Yunnan are 2320.159 million yuan and 2731.248 million yuan, are 14.7 times and 6.7 times the Tibet's
84.317 million yuan. In 2009, the added values of cultural industries in Guangxi and Yunnan are 2320.159 million yuan and 2731.248 million yuan respectively, 5.1 times and 6.0 times the Tibet's (see Table 1.). Generally, the overall scale of cultural industries in China's minority regions expands increasingly, and the speed of development are faster than national average, but the disparity between the internal region and external region is still great.

\subsection{Effects and Structures: Promote the Region- al Employment and Economic Development, but the Industrial Structure is Unreasonable.}

Such industries like industrial manufactures, high and new technologies, modern services are hardly comparable with the same industries in eastern coastal regions, however, breaking out from the development of cultural resources with characteristics and cultural industry is the most effective way to enhance advantages and avoid disadvantages to make a progress. Although at present, the added values of cultural industries in China's minority regions as a share of GDP is still is not higher, except Yunnan, cultural industries in other minority regions as a share of GDP is lower than national average. But in the view of the present development momentum of cultural tourisms and industries in minority regions, we can not underestimate its potentials, as its direct and indirect economic contributions are great. Firstly, the development of cultural industries drives regional employments, against the background of "Capital Deepening" and "Technology Deepening", the trend of technology and capital replacing "Labor" is increasingly obvious in minority regions. In the context of industrial structure optimization and transformation in development mode in minority regions, driving the employment for local residents is a bid problem necessary to solve in minority regions. Cultural industry is the much stronger to promote employment. According to international experience, a direct employment of cultural industry can provide five to seven indirect jobs. On this basis, the number of direct-employed persons of cultural industries 
Table 2. The Workers' Remunerations of Cultural Industry in China's Minority Regions and Net Product Tax Unit: 1000 yuan

\begin{tabular}{|c|c|c|c|c|c|c|c|c|c|c|}
\hline \multicolumn{2}{|c|}{} & $\begin{array}{c}\text { Inner } \\
\text { Mongolia }\end{array}$ & Guangxi & Guizhou & Yunnan & Tibet & Qinghai & Ningxia & Xinjiang & $\begin{array}{c}\text { Minority } \\
\text { Regions }\end{array}$ \\
\hline \multirow{4}{*}{$\begin{array}{c}\text { Remunera } \\
\text {-tion for } \\
\text { Workers }\end{array}$} & 2004 & 282411 & 483240 & 208363 & 462997 & 75092 & 70014 & 131761 & 1988714 & 1988714 \\
\cline { 2 - 11 } & 2005 & 279640 & 268003 & 177004 & 387813 & 86134 & 84621 & 117597 & 1634309 & 1634309 \\
\cline { 2 - 11 } & 2006 & 354774 & 561405 & 316855 & 628047 & 64343 & 94202 & 142028 & 2554879 & 2554879 \\
\cline { 2 - 11 } & 2008 & 535921 & 805664 & 441261 & 1286844 & 147927 & 148148 & 254561 & 4152748 & 4152748 \\
\cline { 2 - 10 } & 2009 & 891842 & 1061033 & 655627 & 1034150 & 197772 & 272445 & 288284 & 5168313 & 5168313 \\
\cline { 2 - 10 } & $\begin{array}{c}\text { Growth } \\
\text { Rate }\end{array}$ & $25.86 \%$ & $17.03 \%$ & $25.77 \%$ & $17.44 \%$ & $21.37 \%$ & $31.23 \%$ & $16.95 \%$ & $21.05 \% \%$ & $21.05 \%$ \\
\hline
\end{tabular}

in minority regions is about one million. By this calculation, the indirect-employed persons are between five millions and seven millions, and this not only be conducive to solve current employment problems in minority regions, but also relieves the pressure caused by rapid disordered surplus labor from the rural minority regions to the eastern developed areas as well as western provincial cities. Secondly, improve the inhabitants' incomes in minority regions. Cultural industries and inhabitants' incomes are reason-result relationships. The increase in residents' incomes level can promote cultural consumptions and drive the development of cultural industries. On the other hand, cultural industries can promote the improvements of residents' incomes. The driving force of cultural industries is powerful, and the incomes of workers of this industry are higher than the other industries, so, its development can greatly promote the residents' incomes. In the view of the situations of workers' remuneration of cultural industries in recent 6 years, in 2004, the workers' total remunerations of cultural industries in minority regions are 1988.714 million yuan, in 2009, rising to 5168.313 million yuan, growing $21.05 \%$ per year, among which average annual growth rate of Qinghai was up to $31.23 \%$, and Inner Mongolia and Guizhou all exceeded $25 \%$, and the lowest Ningxia was up to $16.9 \%$, far exceeding the speed of economic development and the growth rate of the incomes of urban and rural residents of same period. (see Table 2)

The industrial structure is still unreasonable while the cultural industries in China's minority regions are developing rapidly. The data from China's Cultural Relics Statistical Yearbook in 2011 indicate that the main characteristic is relatively single industrial structure, emphasizing culture tourism, and the proportions of the core press and publication industry as well as the film animation industry are lower. Take Guangxi as an example, the added values of cultural industries in Guangxi are 18.021 billion yuan, as $1.88 \%$ proportions of the whole region's GDP, among which the added values of core layer are 5.901 billion yuan, accounting for $32.7 \%$. The added values of perisphere are 7.909 billion yuan, taking up $43.9 \%$, and the related layer are 4.211 billion yuan, accounting for $23.4 \%$. The ratios of the three are 32.7 to 43.9 to 23.4 . in the view of employment, the proportion of the core employees is $23 \%$, mainly focusing on publications, radio and TV public services, literary and artistic creations, show businesses, mass cultural activities; perisphere employees account for $40.5 \%$, mainly focusing on entertainments, Internet, advertisements, Internet bars, etc.; the employees of related layers take up 36.5\%, mainly focusing on toy manufacturing, handicrafts manufacturing. The data above show that the output values and employment proportion of cultural industries in core layer in Guangxi are not higher, remaining at around $30 \%$. Besides, in the view of revenue structures of the subordinate institutions of the Cultural Relics Ministry in China's minority regions, the proportion of the incomes of art performance troupes is the highest, taking up $28.34 \%$, second is mass culture and museum, respectively accounting for $23.62 \%$ and $14.30 \%$. Other departments' proportions are less, and there is a certain degree of structural imbalance.

\subsection{The Cultural Resources with Characteris- tics is Abundant, but the Cultural Infrastruc- ture is Backward.}

China's minority region is characterized by abundant cultural resources, which can be divided into two major categories: the first is physical cultural resources, which are obvious, concrete, appreciable cultural resources with externalities outside national cultures. These resources include national natural ecological system resources such as the Yunnan Red River State Terraces Ecosystem, the Hulunbuir Prairie Ecosystem, the Snow-covered Plateau Ecosystem, Xinjiang and Gansu Gobi Desert Ecosystem, etc. as well as the resources of ethnic villages, roads, buildings, the cultural resources of ethnic artifacts and national food. The second is non-material cultural resources. Moreover, from the first, second and third national nonmaterial cultural heritage lists released in China, we can see that the number of national intangible cultural heritage are 494, accounting for $44.15 \%$ of the total number of 1119 projects, far exceeding the average level of each province, among which the national intangible cultural heritages in Guizhou and Yunnan are more than 90 items.

Abundant cultural resources is only having the potential of developing cultural industries, and cultural infrastructures and capital investments play the important role in the development of cultural industries. Since China's reform and opening up, the cultural construction has experienced the transformation from developing mass culture to the construction of public 
Table 3. The Public Cultural Services System in Minority Regions in 2009

\begin{tabular}{|c|c|c|c|c|c|c|c|}
\hline Regions & $\begin{array}{c}\text { Art } \\
\text { performance } \\
\text { troupes }\end{array}$ & $\begin{array}{c}\text { Art } \\
\text { performance } \\
\text { venues }\end{array}$ & Museums & $\begin{array}{c}\text { Public library } \\
\text { collections } \\
(1000 \text { volume })\end{array}$ & $\begin{array}{c}\text { Provincial and } \\
\text { municipal } \\
\text { cultural center }\end{array}$ & $\begin{array}{c}\text { County } \\
\text { cultural center }\end{array}$ & $\begin{array}{c}\text { Township } \\
\text { cultural center }\end{array}$ \\
\hline $\begin{array}{c}\text { Inner } \\
\text { Mongolia }\end{array}$ & 120 & 28 & 46 & 8704 & 13 & 102 & 905 \\
\hline Guangxi & 135 & 24 & 62 & 17597 & 15 & 99 & 1140 \\
\hline Guizhou & 61 & 9 & 53 & 8003 & 8 & 87 & 1419 \\
\hline Yunnan & 146 & 34 & 113 & 15079 & 13 & 135 & 1365 \\
\hline Tibet & 29 & 22 & 2 & 500 & 7 & 49 & 239 \\
\hline Qinhai & 30 & 21 & 187.1 & 4023 & 8 & 43 & 243 \\
\hline Ningxia & 47 & 16 & 6 & 4350 & 17 & 19 & 224 \\
\hline Xinjiang & 136 & 21 & 63 & 9338 & 15 & 94 & 1072 \\
\hline Aggregate & 704 & 175 & 363 & 67594 & 86 & 628 & 6607 \\
\hline
\end{tabular}

cultural service system. Before the 1990s, the lack of public cultural service facilities prevails in minority regions. After entering the new century, the public service system in minority regions has further developed and improved. Statistics show that the total amounts of art performance troupes in 8 minority regions and provinces reached to 704 in 2009 , the performing art venues reached to 175 , the total books in public libraries reached to 67594 , and the number of museums was 363 , increased by 3 times to 5 times than that of the year 1978 (see Table 3.). Meanwhile, the services systems of "Three Levels of Public Cultural Centers" including provincial and municipal cultural center, county cultural center and township cultural center are basically formed, which effectively met the needs of cultural services in minority regions. In recent years, China pays much attention to infrastructure investments in cultural industries in minority regions. From the year 2000 to 2010, investments in infrastructure of cultural industries in China's 8 minority regions and provinces are up to 602.657 million yuan, accounting for $14.03 \%$ of the national total investments. From the dynamics perspective, before 2005, China's investments in infrastructure of cultural industry in minority region are less, investing more after 2006. From the perspective of the situations of each minority region and province, the infrastructure investment in Yunnan, Inner Mongolia and Xinjiang is higher than that of other provinces. Generally speaking, the infrastructures of cultural industries in China's minority regions are still backward, and the cultural infrastructure investments' channel is single. Mainly depending on state and government investment, infrastructures and capital stock levels are backward far away in east and central section districts.

\section{The Strategies to Promote Market Competitiveness of Cultural Industries in China's Minority Regions}

\subsection{Integrating the Resources of Production Factors, Removing the Bottlenecks of Industrial Developments}

From the micro perspective, factors integration is the necessary means for cultural enterprises to develop and manage.

From the macro perspective, factors integration is the strategic work of regional governments. From the perspective of the development of cultural industries in China's minority regions, the integration of cultural industry resources indicates that the local government and the relevant cultural enterprises and institutions identify and select, allocate and optimize, activate and fuse the resources of different levels, different structures and different contents, making them possess strong openness, value and organization so as to let the whole cultural industry system be in the state of dissipative structure with more creativities and innovations. Specifically, firstly, attempting to integrate cultural resources, and making concerted efforts to create high-quality cultural tourist route. China's minority regions have abundant cultural tourist resources, but recently, the effective interregional cooperation is rare, from the operation perspective, the first is China's minority regions can be integrated into a tourist circle of three religious cultural tourist routes including Buddhist cultural tourism centered on Tibet, Taoism cultural tourism centered on Sichuan and Islam tourism centered on Xinjiang. The second is northern historical and cultural tourist route centered on the Silk Road. The third is national cultural tourist route of Yunnan, Guizhou and Sichuan characterized by the Ancient Tea Horse Road. Secondly, modify human resources. and talent is the core factor of cultural industry resources. At present, China's minority regions lack top-leveled cultural industry leaders, universal backbone talents good at technological development and management, as well as the compound senior personnel with professional skills familiar with cultural characteristics of minority regions. Therefore, in the construction of talents, firstly, we should focus on the combination of talents introduction and internal training; secondly, emphasizing the combination of leaders introduction and universal talents introduction in cultural industry; thirdly, paying much attention to the combination of talents' school educations and on-the-job trainings. Only by realizing talent resources integration in multiple ways can the potentials of cultural industry development be exploited extremely. Thirdly, integrate capital resources. The capital is the blood of cultural industry development, 
and because of lack of capitals for a long time in China's minority regions, many excellent cultural industry projects are hardly implemented. Small cultural industries fail to develop and grow stronger, and large cultural industries are hardly to move toward international. Hence, the first is to actively strive for the national cultural industry development funds to receive the support of our nation; the second is accumulating development funds by means of self-dependence and the strategy of increasing income and reducing expenditure; the third is attracting foreign businesses and investments to pioneer the channels of social and private investments As long as adopting the three pronged approaches, China can remove the bottlenecks of cultural industries in minority regions.

\subsection{Pioneering Cultural Consumption Markets, Paying Equal Attention to Social Benefits and Economic Benefits}

Cultural consumption market determines the direction and potential of cultural industry development, and pioneering consumption market is the foundation of cultural industry development in western minority regions. First and foremost, have a good understanding of the characteristics of market demands, then, subdivide the market. Namely, divide the unified big market into a number of market segments according to diversities of different consumers' cultural demands. For example, kids like toys, animations, comic strips; teenagers like playing games; youth like tourism, movies, pop music; the elderly like watching traditional operas, classics. Having an understanding of these diversities of different consumer groups, the cultural enterprises can lock consumption target and produce cultural products with mass basis and consumption potentials. Secondly, strive for improving residents' incomes, and exploit the consumption potential of cultural industries. On the one hand, improving the social security system or increasing subsidies for cultural products consumption so as to increase residents' consumptions. On the other hand, make every endeavor to improve residents' income by means of multiplier effects to drive developments of cultural industries. Practice of foreign countries indicates that the cultural demands will present injection well typed growth when residents' income exceed \$3000. At present, the local residents' income in minority regions is far away from this threshold, but per capita incomes of residents in abroad and most eastern and central regions have surpassed beyond this red line. So, western minority regions should actively pioneer external market, strengthen advocating, translate cultural resources into economic wealth. Last but not least, foster new areas of cultural consumptions. With popularization of network technologies and digital technologies, new consumption items such as mobile videos, network novels, mobile net games have sprung up everywhere, and the person who can seize the era opportunity can walk in the forefront of the cultural industry development.

Although western minority regions do not have advantages in respect of technology, the extensive consumer groups and demands markets in western regions are the great driving force. If it can cultivate some cultural leading enterprises and innovate business modes while undertaking technologies in developed regions, China is bound to promote cultural industrial structure optimization and upgrading.

\subsection{Promoting the Development of Industrial Agglomeration, Guiding the Private Enterprises to Join}

Realizing the values of cultural products is closely connected with the extension and cohesion of industrial chains. Extension of the industrial chains and cluster development of upstream and downstream enterprises are the effective ways to increase the added values of cultural industries, at the same time, beneficial for effective connection of cultural industries. Cultural industrial cluster development can not only realize the integration of elements resources, information resources sharing, saving costs, but also produce ripple and associated effects to drive the development of regional relevant industries, for example, cultural enterprises agglomeration regions are those developed regions boasting of catering, traffic, housing, finance, etc. China's minority regions gave a large number of cultural industries with diversified contents, but industries lack close connections. Therefore, on the one hand, the government should fully exert its function of coordination, promoting contacts and alliances of the upstream and downstream of regional cultural industries by means of attracting investments through cultural industrial chains and construction of cultural industry park. On the other hand, strengthen constructions of cultural industries with characteristics. Cultivate high-quality cultural industry parks and improve development environments of cultural industries in virtue of national cultural resources with characteristics and the support of relevant national preferential policies. At present, parts of minority regions attempt to move forward to this aspect. For example, after many years of cultivations, recently, Qinghai has established the nation's largest Kunlun Jade Theme Culture Communication Center and the nation's largest Tibetan Plateau Natural Museum regarding disseminating natural ecological and geographical landscapes of Tibetan Plateau, promoting ecological environmental protection as its purposes, and highlighting Tibetan Plateau cultural industry system with characteristics as its purposes. In general, cultural industrial clusters of minority regions exist only in capital cities such as Chengdu, Kunming, Nanning, Lanzhou, etc.. The industries in the vast majority of small and medium-sized cities scattered, and cultural industrial chains are still incomplete.

\section{Conclusion}

China's minority regions are natural museums of national cultures, abundant, unique, original ecological culture resources as the important development foundation of cultural industrial market competitiveness. However, there is a problem of developing slowly, unreasonable industrial structures, backward cultural infrastructures which hinders its road to transform the 
resources' advantages to industrial advantages. And this requires integrating the resources of production factors, removing the bottlenecks of industrial developments; pioneering cultural consumption markets, paying equal attention to social benefits and economic benefits; promoting the development of industrial agglomeration, guiding the private enterprises to join to really strengthen the market competitiveness of cultural industries in China's minority regions.

\section{References}

[1] Wang Yan. Research on Relationships between The National Cultural Industry and The National Regional Economic Growth [D]. Central University for Nationalities, 2007

[2] Zhao Ling. The Problems of Diversity in the Development stra- tegies of Cultural Industries in Western Minority Regions [J]. Academic Exploration, 2001, S1:156-157.

[3] Yuan Mingxu. the Theory of Local Government Functions in the Development of Cultural Industries in Minority Regions [J]. Thinking, 2008,01: 50-55.

[4] Li Shiju. Enhance The Competitiveness of Cultural Industries in Minority Regions [J]. Journalism Lover, 2011,18: 153-154.

[5] Huang Xiaojun. The Research on The Construction on New Countryside Culture in Frontier Multi-ethnic Areas [D]. Yunnan University, 2012.

[6] Li Wei. Evaluation studies on the competitiveness of cultural industries in Hunan Province [D]. Central South University, 2010

[7] [7] Xiang Zuoyi. Studies on the Development of Circulation Industries in Minority Regions [D]. Central South University, 2012.

[8] Meng Laiguo. Studies on Development Strategies of Cultural Industries in China's Western Minority Regions [J]. Academic Exchange, 2013,08:200-203. 